\title{
PENILAIAN RISIKO MULTI BENCANA DI JAKARTA, INDONESIA
}

\author{
Uzlifatul Azmiyati $^{1}$, Nofita Sustiwi Poernomo ${ }^{2}$ \\ ${ }^{1}$ Program Studi Teknik Lingkungan Universitas Nahdlatul Ulama NTB, Mataram \\ ${ }^{2}$ Program Studi Geoinformasi untuk Manajemen Bencana Universitas Gadjah Mada, Yogyakarta \\ u.azmiyati@gmail.com
}

\begin{abstract}
Abstrak. Jakarta adalah ibu kota Negara Indonesia, secara geografis terletak di $6^{0} 12$ 'Lintang Selatan dan $106^{0} 48^{\prime}$ Bujur Timur. Sebagai ibukota Negara, Jakarta tidak kebal dari ancaman bencana. Diperlukan langkah yang tepat untuk meminimalkan kerugian yang mungkin ditimbulkan oleh sejumlah potensi bencana yang dapat terjadi di Jakarta. Salah satu langkah yang dapat dilakukan adalah melakukan penilaian risiko multi bencana, sebagai langkah awal untuk membantu manajemen bencana. Metode yang digunakan dalam studi penilaian risiko multi bahaya adalah modifikasi dari metode yang dikembangkan oleh Stefan Greiving (2006). Penilaian risiko multi bencana yang telah dilakukan menghasilkan peta risiko terintegrasi. Penilaian risiko terpadu multi bencana mencakup empat elemen yaitu peta bencana, peta bencana berisi informasi tentang jenis-jenis bencana yang mungkin terjadi. Dari peta bencana kemudian dibuat peta bahaya terintegrasi. Setelah itu dianalisis kerentanan wilayah dan ditampilkan sebagai peta kerentanan. Peta kerentanan disusun berdasarkan informasi paparan lokasi terhadap bencana, dan berdasarkan kapasitas lokasi. Analisis terakhir adalah membuat peta risiko terintegrasi yang berisi kombinasi peta bencana terintegrasi dan peta kerentanan. Analisis telah dilakukan sehingga menghasilkan distribusi spasial kejadian multi-bencana, multi-kerentanan, dan peta risiko terintegrasi di wilayah Jakarta. Peta risiko terintegrasi yang dihasilkan menunjukkan bahwa wilayah berisiko tinggi berada di utara dan barat Jakarta. Sementara itu risiko bencana yang rendah ada di wilayah timur dan selatan Jakarta.
\end{abstract}

\section{Kata kunci: Jakarta; Kerentanan; Penilaian Risiko Multi Bencana; Peta risiko Terintegrasi}

\section{PENDAHULUAN}

Indonesia adalah salah satu negara yang sangat rentan terhadap bencana alam. Baik dalam bentuk bahaya geologi, hidrometeorologi, bahaya sosial dan biologi. Hampir semua daerah di Indonesia memiliki potensi bencana yang luas, termasuk Jakarta. Jakarta sebagai ibu kota Indonesia tidak luput dari bencana yang dapat menyebabkan kerusakan, kehilangan atau kerugian bagi penduduk. Bencana yang berpotensi terjadi di Jakarta adalah banjir, badai, amblesan, tanah longsor, gelombang pasang, konflik sosial, aksi terorisme, dan kebakaran. Bencana terbesar yang mengancam Jakarta adalah banjir, banjir di Jakarta selalu terjadi setiap tahun dengan ancaman perluasan wilayah. Tercatat bahwa sebagian besar banjir besar terjadi pada 2013 dengan frekuensi kejadian 33 kali, yang menyebabkan (dibi.bnpb.go.id).

Peran Jakarta sebagai ibu kota Negara harus dipertimbangkan dalam manajemen bencana karena Jakarta memiliki tingkat kerentanan yang tinggi terhadap bencana. Penelitian ini bertujuan untuk melakukan penilaian risiko multi bahaya, yang merupakan proses melakukan penilaian bahaya, kemudian melakukan penilaian kerentanan, memberikan saran kepada perencanaan daerah, untuk melakukan manajemen risiko di Jakarta. Informasi tentang penilaian risiko multi bahaya sangat penting untuk mengurangi risiko bencana di suatu daerah, dalam hal ini bencana di Jakarta. Dengan penilaian risiko multibahaya dapat menjadi referensi yang lebih baik dalam perencanaan tata ruang dan manajemen bencana.

\section{KARAKTERISTIK WILAYAH STUDi}


Jakarta secara geografis terletak di $6^{0} 12$ 'Lintang Selatan dan $106^{\circ} 48^{\prime}$ Bujur Timur, adalah dataran rendah dengan ketinggian ratarata 7 meter di atas permukaan laut. Namun, sekitar 40 persen wilayah Jakarta yang dataran permukaannya 1-1,5 meter di bawah permukaan laut. Secara geologis, seluruh wilayah Jakarta adalah dataran aluvial, material tanahnya merupakan hasil pengangkutan sedimen dan limpasan air sungai di daerah tersebut. Jakarta terdiri dari sedimen Pleistosen yang ditemukan di sekitar 50 meter di bawah permukaan tanah, di mana bagian selatan terdiri dari lapisan aluvial, sedangkan pantai dataran rendah hingga bentangan daratan sekitar 10 kilometer. Ada lapisan sedimen yang tidak terlihat lebih tua di permukaan tanah karena seluruhnya terkubur oleh pengendapan aluvium.

Jakarta memiliki wilayah pantai yang cukup luas, yaitu sekitar $155,01 \mathrm{~km}^{2}$. Wilayah ini membentang dari timur ke barat sepanjang sekitar $35 \mathrm{~km}$ dan memanjang ke tanah antara 4 $\mathrm{km}$ hingga $10 \mathrm{~km}$. Wilayah pesisir Jakarta adalah pantai yang beriklim panas dengan suhu rata-rata $28,50{ }^{\circ} \mathrm{C}$ dan kelembaban rata-rata 72 persen.

Berdasarkan lokasinya, Jakarta termasuk kota delta yaitu kota yang terletak di muara sungai. Kota delta umumnya terletak di bawah permukaan laut dan sangat rentan terhadap perubahan iklim. Kota delta Jakarta dilalui oleh 13 aliran dan sungai yang terkena pasang surut. Tiga belas sungai dan dua kanal yang melewati Jakarta sebagian besar berujung di Jawa Barat dan bermuara di Teluk Jakarta. Kondisi iklim di wilayah Jakarta di bawah stasiun pengamatan Jakarta pada tahun 2011 memiliki suhu udara rata-rata $28,4^{\circ} \mathrm{C}$ dengan kelembaban udara 74 persen, tekanan udara 1009,6 mbs, arah angin 270 titik, kecepatan angin 2 mill/jam, matahari bersinar 45 persen dan curah hujan rata-rata $2,395 \mathrm{~mm}^{2}$.

Sebagai ibu kota Negara, Jakarta telah menjadi kota multi fungsi. Memiliki berbagai fungsi penting secara nasional, seperti: pusat pemerintahan negara, pusat kegiatan ekonomi, kegiatan pendidikan dan pusat kebudayaan. Selain menjadi pusat pemerintahan dan ekonomi, Jakarta juga menjadi salah satu tujuan wisata. Jakarta sebagai tujuan wisata menghadirkan keanekaragaman budaya dan tempat bersejarah. Selain itu, ketersediaan tenaga kerja dengan berbagai keahlian dengan populasi yang besar, berpotensi memberikan efek yang sangat menguntungkan pada kegiatan pembangunan.

Selain memiliki banyak manfaat potensial, Jakarta juga memiliki potensi bencana. Berdasarkan Badan Nasional Penanggulangan Bencana (BNPB) ada banyak potensi bencana di Jakarta, seperti: banjir, gelombang pasang, tornado, gempabumi, aksi teroris, kecelakaan transportasi, peristiwa luar biasa (penyakit endemik), konflik sosial, kebakaran, dan amblesan/penurunan tanah (land subsidence). Salah satu potensi bencana terbesar di Jakarta adalah banjir, ini disebabkan karena Jakarta dilintasi beberapa sungai dan penurunan tanah yang dalam beberapa tahun terakhir telah menurun secara dramatis. Selain itu, peningkatan pertumbuhan populasi dan penggunaan lahan yang tidak teratur juga berdampak pada tingkat keparahan yang diakibatkan oleh bencana.

\section{METODE PENELITIAN}

Studi risiko bencana menggunakan pendekatan metode sebagai berikut:

Risiko Bencana $\approx$ Ancaman $* \frac{\text { Kerentanan }}{\text { Kapasitas }}$

Gambar 1. Persamaan untuk Penilaian Risiko Bencana, berdasarkan Perka No. 2 BNPB

Metode pendekatan yang digunakan dalam penelitian ini dilakukan dalam beberapa tahap, yaitu:

Perumusan Faktor Risiko Bencana

Dalam perumusan risiko bencana, beberapa faktor yang digunakan adalah:

a. Faktor Bahaya 
Faktor bahaya terdiri dari banjir, gelombang pasang, angin kencang, dan penurunan muka tanah (land subsidence)

b. Faktor Kerentanan

Faktor kerentanan terdiri dari beberapa subfaktor, yaitu: kerentanan sosial dan demografi

c. Faktor Kapasitas

Faktor kapasitas dengan sub-faktor terdiri dari sumber daya alam, sumber daya buatan, dan kebijakan pemerintah

1. Langkah selanjutnya adalah penentuan indikator masing-masing faktor / sub-faktor. Penentuan indikator berdasarkan literatur untuk analisis risiko bencana.

2. Penentuan bobot masing-masing faktor, sub faktor, dan indikator yang telah dibentuk menggunakan proses hierarki analitis (AHP) yang dikembangkan oleh Thomas L pada tahun 1970. AHP adalah metodologi pengukuran dengan perbandingan berpasangan dan mengandalkan penilaian dari ahli untuk mendapatkan skala prioritas. Ini adalah skala yang mengukur bentuk relatif. Perbandingan dibuat dengan menggunakan skala penilaian absolut, yang mewakili berapa banyak indikator mendominasi yang lain sehubungan dengan bencana tertentu.

3. Analisis risiko bencana untuk multibencana dengan mengukur faktor-faktor yang dipertimbangkan, sub-faktor, dan indikator. Pengukuran faktor tertimbang dilakukan dengan standarisasi nilai indikator. Faktor-faktor yang dipertimbangkan berdasarkan perbandingan dibuat dengan menggunakan skala penilaian absolut, yang mewakili berapa banyak indikator yang mendominasi yang lain sehubungan dengan bencana tertentu. Mengukur faktor-faktor risiko bencana dengan menjumlahkan semua penggandaan nilai dari nilai mentah masing-masing indikator dengan masing-masing bobot dalam setiap faktor.

4. Reklasifikasi risiko bencana berdasarkan bahaya, kerentanan, dan kapasitas dengan metode penilaian. Perumusan risiko bencana dikelompokkan berdasarkan tingkat nilai.

5. Akhir dari langkah ini adalah pemetaan untuk risiko bencana berdasarkan multibencana di Jakarta menggunakan Sistem Informasi Geografi (SIG). Langkah-langkah pemetaan menggunakan teknologi SIG berdasarkan Perka No.2 Tahun 2012 dari BNPB, yaitu:

a. Membuat kisi (Grid) (dari sumber vektor)

b. Merger dan memotong layer grid

c. Definisi rentang warna yang digunakan untuk mewarnai kisi dan legenda

d. Analisis kisi tertentu (kemiringan kisi, kisi 'jarak objek', dll.)

e. Penghitungan kisi (Grid Calculation)

f. Klasifikasi dan kurangi kisi pada kontur lapisan kisi

g. Persiapan statistik ringkasan dan grafik Berdasarkan langkah di atas dapat disimpulkan dengan diagram alur berikut ini:

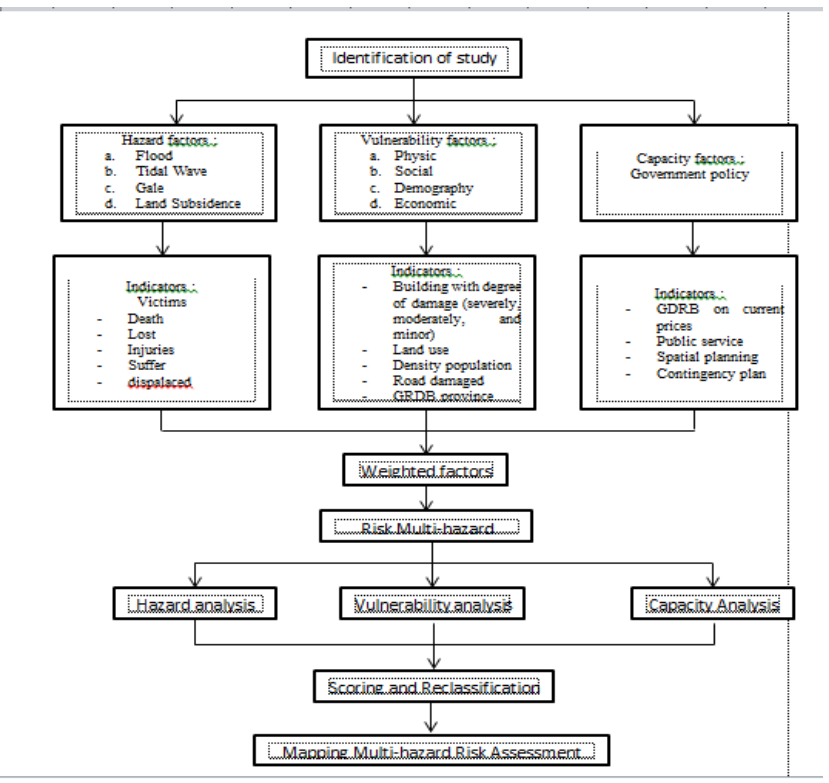

Gambar 2. Diagram Alur Penilaian Risiko Multi Bencana

\section{HASIL DAN PEMBAHASAN}

Hasil dari penilaian risiko multi bencana adalah sebagai berikut:

Bahaya (Hazard)

'DKI Jakarta adalah daerah rawan bencana. Beberapa bencana yang bisa terjadi di 
DKI Jakarta antara lain: banjir, angin kencang, gelombang pasang, dan penurunan muka tanah (land subsidence). Setiap bahaya memiliki nilai bobotnya sendiri. Nilai pembobotan dimaksudkan untuk menentukan bencana yang paling memberikan dampak terbesar di wilayah DKI Jakarta. Berdasarkan peta multi-bahaya dapat ditunjukkan bahwa distribusi bahaya secara spesifik seperti yang ditampilkan pada Gambar 3.

Peta multi-bencana DKI Jakarta menunjukkan bahwa bahaya yang terjadi di DKI Jakarta termasuk bahaya banjir, kenaikan permukaan laut, angin kencang, dan bahaya penurunan muka tanah. Berdasarkan peta terlihat bahwa bahaya tinggi di wilayah utara dan barat DKI Jakarta. sementara itu bahaya rendah di wilayah selatan DKI Jakarta.

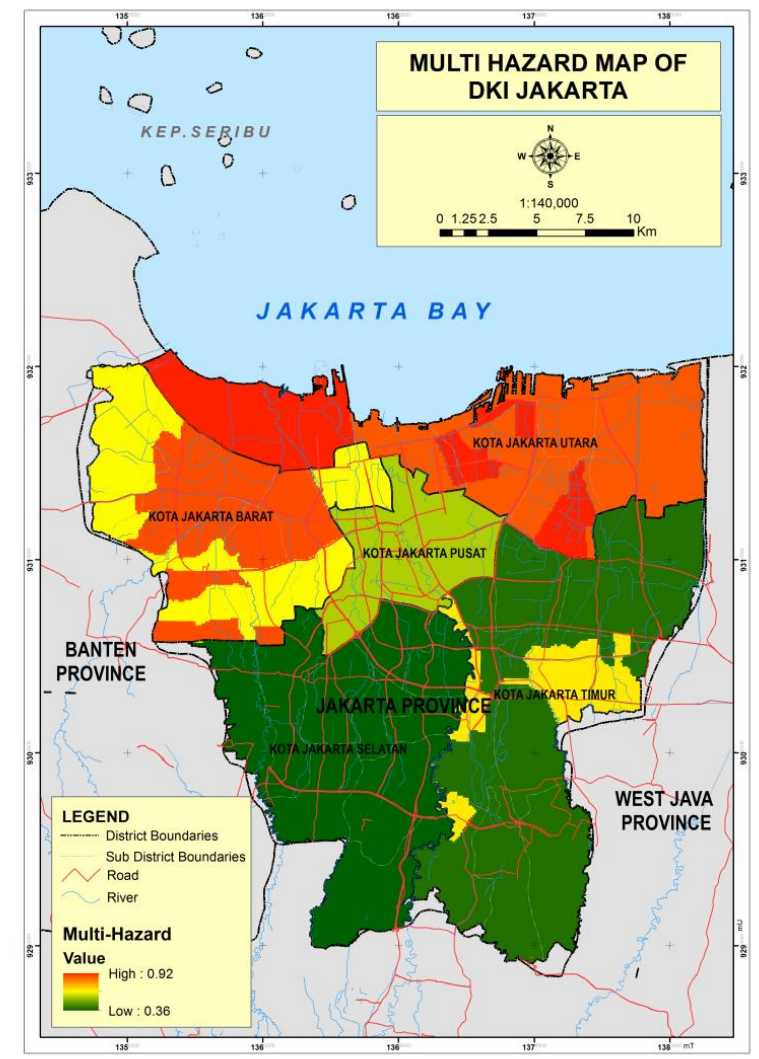

Gambar 3. Peta Multi Bencana di DKI Jakarta

Tabel berikut menunjukkan nilai pembobotan untuk multi-bencana:
Tabel 1. Nilai Pembobotan untuk Setiap Bencana

\begin{tabular}{|l|l|l|l|l|l|}
\multicolumn{1}{|c|}{ Wilayah } & Luas (km) & Banjir & $\begin{array}{c}\text { Penurunan } \\
\text { Muka } \\
\text { Tanah }\end{array}$ & $\begin{array}{c}\text { Angin } \\
\text { Kencang }\end{array}$ & $\begin{array}{c}\text { Kenaikan } \\
\text { Permukaan } \\
\text { Laut }\end{array}$ \\
\hline Jakarta Utara & 137.93 & 0.2 & 0.4 & 0.1 & 0.3 \\
\hline Jakarta Barat & 124.84 & 0.3 & 0.44 & 0.11 & 0.11 \\
\hline Jakarta Pusat & 47.79 & 0.3 & 0.4 & 0.2 & 0.1 \\
\hline Jakarta Timur & 184.27 & 0.4 & 0.2 & 0.1 & 0.3 \\
\hline Jakarta Selatan & 144.53 & 0.4 & 0.3 & 0.2 & 0.1 \\
\hline
\end{tabular}

Sumber: Analisis Data, 2014

\section{Kerentanan (Vulnerability)}

Kerentanan dipahami secara luas sebagai kecenderungan untuk disakiti jika suatu peristiwa melampaui ambang batas tertentu (meskipun sekali lagi tidak jelas) terjadi dan berdampak pada masyarakat, aset ekonomi, ekosistem, atau infrastrukturnya. Kerentanan dalam penelitian ini berdasarkan pada bangunan, data penggunaan lahan, kepadatan populasi, dan GDRB (Gross Domestik Regional Bruto). Setiap kerentanan akan di overlay menjadi multi-kerentanan. Penambahan ini menunjukkan multi-kerentanan bahaya di DKI Jakarta. Berdasarkan peta Kerentanan, ditunjukkan bahwa kerentanan tinggi di Provinsi Jakarta Pusat sedangkan kerentanan rendah di Wilayah Jakarta Utara. Multi kerentanan di DKI Jakarta diperlihatkan pada Gambar 4. 


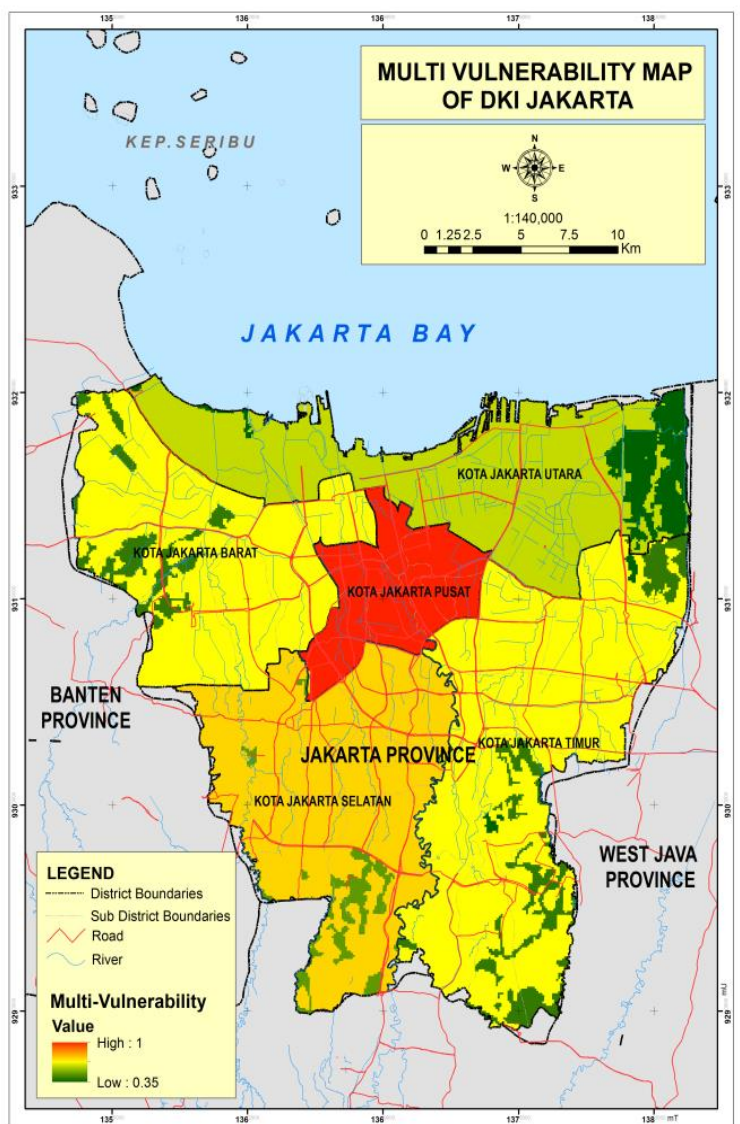

Gambar 4. Peta Multi Kerentanan di DKI Jakarta

\section{Penilaian Risiko untuk Peta Risiko}

\section{Terintegrasi (Integrated Risk Map)}

Peta Risiko Terintegrasi (Integrated Risk Map) diperoleh dari hasil persimpangan antara multi-bahaya dan kerentanan. Tetapi sebelum melakukan overlay kita harus menentukan skor. Metode penilaian dipilih karena lebih mudah daripada yang lain dalam perhitungan dan pengambilan keputusan. Di bawah ini adalah deskripsi untuk penilaian dan klasifikasi untuk menentukan tingkat penilaian risiko.

Tabel 2. Penilaian dan Klasifikasi untuk Penilaian Risiko

\begin{tabular}{|c|c|}
\hline Classification & Scoring \\
\hline High Risk & 1 \\
\hline Medium Risk & 0.679 \\
\hline Low Risk & 0.33 \\
\hline
\end{tabular}

Sumber: Analisis Data dan Perka No. 2 Tahun 2012 BNPB

Peta risiko terintegrasi dihasilkan dari multi-bahaya dan kerentanan. Peta Risiko Terintegrasi (Integrated Risk Map) yang dihasilkan ditampilkan pada Gambar 5. Hasil peta menunjukkan bahwa lokasi berisiko tinggi di Wilayah Utara dan Barat DKI Jakarta. Dan kemudian lokasi berisiko rendah di wilayah DKI Jakarta Timur dan Selatan.

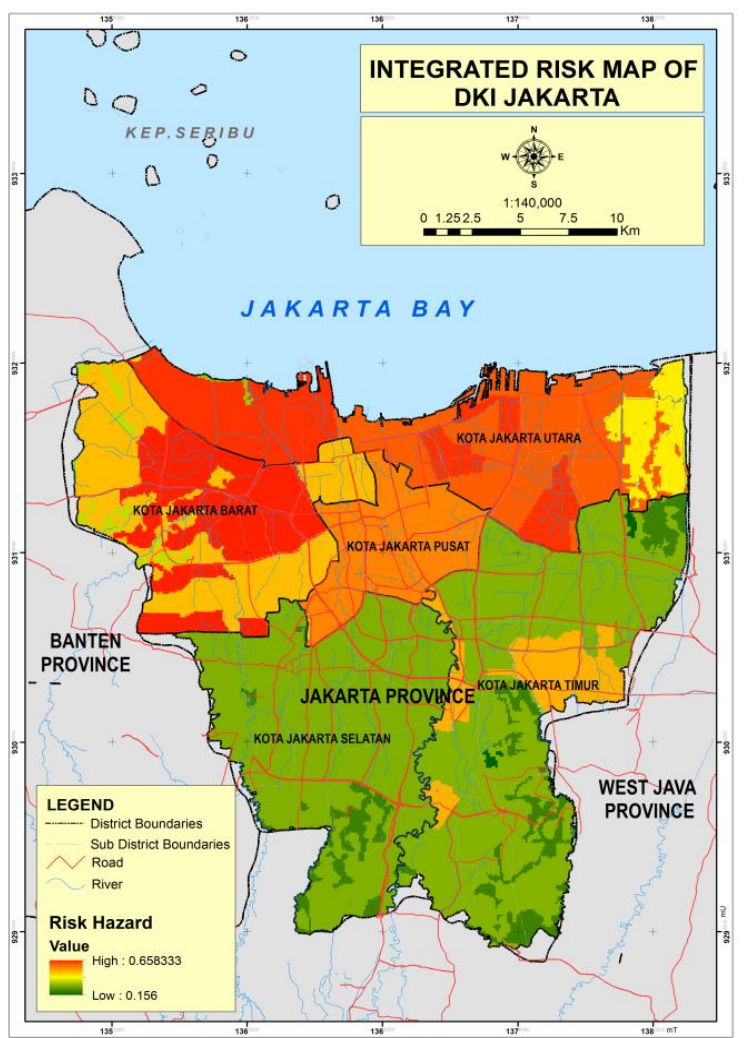

Gambar 5. Peta Risiko Terintegrasi di DKI Jakarta

Distribusi risiko di DKI Jakarta dijelaskan lebih detail pada Tabel 3 dan Gambar 6 berikut ini: 
Tabel 3. Total Area Lokasi Distribusi Risiko di DKI Jakarta (meter)

\begin{tabular}{|c|c|c|c|c|c|}
\hline Wilayah & No data & $\begin{array}{l}\text { Risilko } \\
\text { Rendah }\end{array}$ & $\begin{array}{l}\text { Risiko } \\
\text { Medium }\end{array}$ & $\begin{array}{l}\text { Risiko } \\
\text { Tinggi }\end{array}$ & Total \\
\hline Jakarta Barat & 26.69549 & 529.06802 & 6559.82454 & 5549.2435 & 12664.83155 \\
\hline Takanta Pusat & & 11.35362 & 22.82477 & 4814.4261 & 4848.60449 \\
\hline Jakarta Selatan & 45.32491 & 14566.45728 & 40.32204 & 12.53288 & 14664.63711 \\
\hline Jakarta Timur & 59.54093 & 15973.51033 & 2642.19781 & 21.54965 & 18696.79872 \\
\hline Jakatta Utara & 95.82651 & 76.29428 & 1791.41995 & 12027.86066 & 13991.4014 \\
\hline no data & & 120.73094 & 33.04427 & 77.05897 & 230.83418 \\
\hline Grand Total & 227.38784 & 31277.41447 & 11089.63338 & 22502.67176 & 65097.10745 \\
\hline
\end{tabular}

Sumber: Analisis Data, 2014

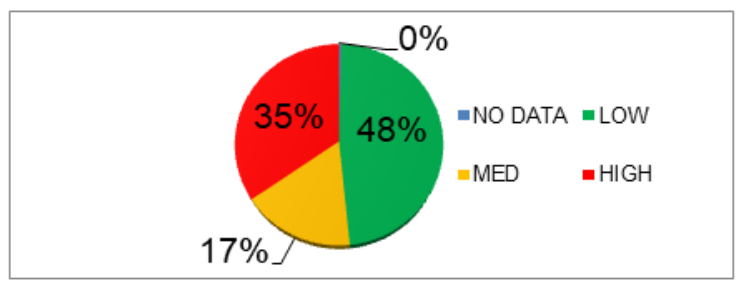

Gambar 6. Presentasi Distribusi Risiko di Wilayah DKI Jakarta

\section{KESIMPULAN}

Penilaian risiko terpadu multi-bahaya mencakup 4 elemen yaitu peta bahaya, peta bahaya berisi informasi tentang jenis-jenis bahaya yang mungkin terjadi. Dari peta bahaya kemudian dibuat peta bahaya terintegrasi. Setelah itu dianalisis kerentanan wilayah dan ditampilkan sebagai peta kerentanan. Peta kerentanan disusun berdasarkan informasi paparan lokasi terhadap bahaya, dan berdasarkan kapasitas lokasi. Analisis terakhir adalah membuat peta risiko terintegrasi yang berisi kombinasi peta bahaya terintegrasi dan peta kerentanan.

Dalam studi ini analisis yang telah dilakukan menghasilkan distribusi spasial dari berbagai peristiwa bahaya, multi kerentanan, dan peta risiko terintegrasi di wilayah Jakarta. Peta risiko terintegrasi yang dihasilkan menunjukkan bahwa wilayah berisiko tinggi berada di utara dan barat Jakarta. Sementara itu risiko bencana yang rendah ada di wilayah timur dan selatan Jakarta.

\section{DAFTAR PUSTAKA}

Abidin H.Z, Andreas H., Gumilar I., Gamal, M., Land Subsidence and Urban Development in Jakarta (Indonesia), 7th
FIG Regional Confrence Hanoi, Vietnam, 2009.

Erwin T. Hasyim, Identifikasi Tingkat Risiko Bencana Gempabumi dan Tsunami Serta Arahan Tindakan Mitigasi Bencana Di Wilayah Pesisir Kabupaten Sukabumi, 2007.

Greiving Stevan. Integrated Risk Assessment of Multi Hazards: A New Methodology. Geological Survey of Finland, Special Paper, 2006, 42:75-82.

Harso H., Linarka U.A., Kurniawan R., Noviati S., Pemanfaatan SATAID Untuk Analisa Banjir dan Angin Putting Beliung: Studi Kasus Jakarta dan Yogyakarta. Jurnal Meteorologi dan Geofisika Volume 12 No. 2, 2011, 195-205.

http://dibi.bnpb.go.id

Jakarta Dalam Angka 2012, Badan Pusat Statistik Provinsi DKI Jakarta, Katalog BPS:1102001.31.

Jorn Birkman, Measuring Vulnerability to Natural Hazards Towards Disaster Resilient Societies, 2006, New York: United Nation University. 